Entrepreneurial drivers, barriers and enablers of computing students: gendered perspectives from an Australian and UK university

Sally Smith ${ }^{\mathrm{a} *}$, Margaret Hamilton ${ }^{\mathrm{b}}$ and Khristin Fabian ${ }^{\mathrm{a}}$

${ }^{a}$ Centre for Computing Education Research, Edinburgh Napier University, Edinburgh, UK;

${ }^{b}$ Department of Computer Science, RMIT University, Melbourne, Australia

*Corresponding author s.smith@napier.ac.uk 


\title{
Entrepreneurial drivers, barriers and enablers of computing students: gendered perspectives from an Australian and UK university
}

\begin{abstract}
This paper investigates computing students' entrepreneurial intentions, motivations, recognisable barriers and encouragements towards entrepreneurship, with a focus on gender. Two universities, one in Australia and one in the UK ( $n=247)$, were used as locations for the research to consider two distinct contexts. In each university there were similarly high levels of interest in entrepreneurship among computing students, however some significant differences in responses were found, especially between male and female participants. Job flexibility was a strong motivation for the UK-based female participants; while female participants at the Australian university identified internal barriers (such as lack of confidence and experience). Enablers to entrepreneurial activity were identified, including access to incubators and academic support. Directing such support towards computing students, while recognising gender differences, could increase interest in, and take-up of, entrepreneurship. Recommendations are made regarding how universities can best support would-be entrepreneurs and encourage inclusive entrepreneurship into the future.
\end{abstract}

Keywords: entrepreneurship, computing, students, gender, IT sector

\section{Introduction}

Entrepreneurship is considered to be key to economic growth and recovery, for example introducing new technology, creating jobs and improving the quality of life (Audretsch, Keilbach, and Lehmann 2006; Urbano, Aparicio, and Audretsch 2018). Indeed, the global economy is changing as a result of technology advances, including the emergence of new models of entrepreneurship facilitated by easy online access to global markets and low financial barriers to entry (OECD 2017). Graduates from computing disciplines (including computer science, web development, business computing and artificial intelligence) are well-placed to take advantage of these new models by leveraging advanced digital skills acquired through university study. Such individuals may be well-placed, but factors serve to encourage or discourage entrepreneurship as a 
career option. Certainly different subject disciplines yield different results, with fields of study relevant in predicting levels of interest in pursuing entrepreneurship (entrepreneurial intention) (Teixeira and Forte 2017). Of particular concern to the computing subject discipline is the underrepresentation of women studying computing in the UK, Australia, US and elsewhere, which impacts on the potential for women entrepreneurs in the Information Technology (IT) industry sector. For example, in the UK less than $20 \%$ of computing students are women (HESA 2017). In Australia, in 2015 the figure was 14\% (Falkner 2017). This is compounded by a lack of women entrepreneurs generally. The population of new female entrepreneurs in the UK has remained static at 5.6\% (compared with the male rate of 11.6\%) (Hart, Bonner, Levie and Heery 2017). In Australia, female participation rates are slightly above the global average with women representing 24\% of start-up founders (Startup Muster 2017). Studies have identified the potential for growth in uptake of entrepreneurship among women (Sauer and Wilson 2016; Humbert and Drew 2010) and there is recent evidence of growth in female participation in IT entrepreneurship (Leadem 2016).

Termed their 'third mission’ (after education and research), universities can facilitate innovation and entrepreneurship through advanced skills development and, for example, fostering links with industry; and are increasingly called upon to do so by governments. However, success with this mission varies with university context and culture (Watson, Hall, and Tazzyman 2016). Possession of the means or skills to become an entrepreneur, or entrepreneurship ability, is generally believed to be the central determinant of entrepreneurial success and recognises the role of both training and experience to increase ability (Naudé 2014; Schneider 2017). Universities are uniquely placed to provide both education to increase knowledge, and infrastructure to increase entrepreneurship experience amongst their students (Jabeen, Faisal, and Katsioloudes 2017; Rae and Melton 2014). Indeed, many university students are positive about becoming an entrepreneur (Shinnar, Pruett, and Toney 2009; Guerrero et al. 2018). University provision of entrepreneurship 
education has been shown to increase both ability and entrepreneurial intention (Nowiński et al. 2017; Wilson, Kickul, and Marlino 2007; Rae and Melton 2014), although how the subject should be taught and assessed is part of an ongoing debate and beyond the scope of this study (for example Nabi et al. 2017). Many universities provide business incubation services such as office space, business advice and access to expensive equipment (Al-Dajani et al. 2014; Jansen et al. 2015). However, while many universities invest considerable resource into business incubators, there are limited notions of success measures, conflicting studies evaluating impact and little awareness of who take up these opportunities (for example Guerrero et al. 2018).

Although many studies have focused on entrepreneurial intention among business students, little research has been undertaken to reveal discipline-specific attitudes to entrepreneurship outside business courses, or for a single discipline in different countries. In particular there is a gap in our understanding of the levels of interest and perceptions of the drivers, barriers and enablers of entrepreneurship for computing students in spite of their potential to create economic growth through advances in IT. So this research explored computing students’ attitudes towards entrepreneurship through a study conducted in an Australian and UK university. The universities were selected based on their similarly large computing provision in city-based locations and their varying approaches to entrepreneurship. The Australian university offers an undergraduate course in IT Entrepreneurship for computing students and recently established a business incubator. The UK university has an established IT-focused business incubator which is promoted to on-campus students. It does not offer entrepreneurship education to computing students, however it is located in a city with many IT start-ups and fosters close working with the IT industry. This study considered the attitudes of computing students towards entrepreneurship (based on institution and gender) that might orient them to make use of these facilities and any associated entrepreneurship education to carve out an entrepreneurial career. The main contribution of the paper is in its consideration of a discipline-specific group across two institutions. The data analysis, which 
highlights both intrinsic and extrinsic motivations, can be used to better inform impactful and inclusive university investment in the development of entrepreneurship ability for their students and graduates.

\section{Entrepreneurship: drivers, barriers and enablers}

Although studies have shown that there is a relatively high level of interest among university students in starting their own business, not all students act on an entrepreneurial intention when they graduate (Shinnar et al. 2018; Shirokova, Osiyevskyy, and Bogatyreva 2016). Extant research on drivers, or motivations, to become an entrepreneur, together with barriers and enablers, can lead to a better understanding of the pipeline through university and into entrepreneurship.

In terms of motivating factors (or drivers), these generally fall into push and pull categories serving to motivate individuals (Humbert and Drew 2010). Pull factors include autonomy, personal satisfaction and aspiration while push factors include unemployment, redundancy and dissatisfaction with the labour market. Pull factors are also framed as drive theories (internal motivations acting to encourage an individual to become an entrepreneur) and incentive theories (motivations such as achievement potential or prestige) (Carsrud and Brännback 2011). The pull of prestige associated with being an entrepreneur, such as positive recognition among family and wider society, varies according to family background and gender (Shinnar, Giacomin, and Janssen 2012; Pruett et al. 2009). Some qualities (or traits) identified as associated with entrepreneurship can be the result of growing up in an environment (both national and domestic) with a culture that views entrepreneurship positively, affecting entrepreneurial intention (Engelen 2010; Kwon and Arenius 2010). So while Miller (2015) identifies self-confidence, a need for achievement, and a desire for independence, these characteristics may not be valued equally by all genders in all cultures. Prior studies into the impact of gender and entrepreneurship indicate that while female participation varies across countries, women generally report lower entrepreneurial intentions 
(Zhao, Seibert, and Hills 2005; Santos, Roomi, and Liñán 2016) and female rates of entrepreneurship are nearly always less than those of males (Thébaud 2010; Schoon and Duckworth 2012; Wilson, Kickul, and Marlino 2007) including for IT entrepreneurship (Frank, Marques, and Lasch 2009).

In terms of barriers, Smith and Beasley’s (2011) study of digital industry graduates in the UK found constraining factors included lack of general business knowledge, lack of sector-specific mentors, lack of finance and experience of familial entrepreneurship. Elsewhere, high levels of interest in entrepreneurship amongst undergraduates has been found, but inadequate business knowledge and perceived risk were found to be deterrents (Wang and Wong 2004). Shinnar et al. (2012) found fear of failure and perceived competence to be barriers, but these were less significant for Chinese students, suggesting this was related to cultural "belief that hard work, rather than ability, determines success” (p. 486). Women have been found to cite more barriers to entrepreneurship compared with men (Santos, Roomi, and Liñán 2016; Marlow and Patton 2005), in particular access to finance (Marlow and Patton 2005; Kwong, Jones-Evans, and Thompson 2012) and support (Shinnar et al. 2012). Studies have shown that social norms lead to women believing entrepreneurship is more suited to men (BarNir, Watson, and Hutchins 2011; Shinnar, Giacomin, and Janssen 2012) and, for women, entrepreneurial intention is more affected by personal attitude and subjective norms than for men (Feder and Niţu-Antonie 2017). Such attitudes and beliefs can act as a barrier: female students have lower entrepreneurial intentions than men, linked to lower levels of self-efficacy related to beliefs that entrepreneurship is a masculine activity (Nowiński et al. 2017).

Factors that act as enablers to entrepreneurship are not widely agreed across studies. Enablers have been found to include co-mentoring from business partners and course content (Smith and Beasley 2011). Access to social capital, for example networks of people from whom to seek advice and funding, has been found to enable entrepreneurship (Casson and Della Giusta 
2007; Light and Dana 2013). Family support in the form of both money and values and behaviours also act as enablers (Schoon and Duckworth 2012). Drawing on universities known for their established reputation for entrepreneurship, a three-stage enablement model (educate, stimulate and incubate) was proposed by Jansen et al. (2015) which makes a number of recommendations to encourage entrepreneurship including supportive faculty, role models, courses, networking and funding. Not all universities have such infrastructure and the lack of universally agreed enablers, places universities at risk of making investments that are not well targeted or inclusive across student groups and disciplines.

\section{Entrepreneurship in the IT industry sector}

The IT sector has a tradition of high profile (male) entrepreneurs who front their organisations at widely-viewed product launches and technology fairs. The IT start-up sector is large and growing, fuelled by innovative ideas and high levels of both education and experience (Frank, Marques, and Lasch 2009); it is characterised by the speed of start-up creation (Stayton \& Mangematin, 2016) and high growth potential (Morris et al. 2018). Kaltenecker, Hoerndlein, and Hess (2015) found having a 'big idea' the biggest factor in entrepreneurial intention for computing students. Meanwhile, Galloway, Kapasi, and Whittam (2015) found little entrepreneurial awareness amongst computing placement students.

Despite strong representation of entrepreneurialism in the IT sector, little is known about how factors such as gender and institutional context influence the development of entrepreneurial ability or interest among computing students. With the aim to better understand computing student attitudes to entrepreneurship, our questions were: for computing students, what plans do they have to become an entrepreneur; what factors might act as motivation to take up entrepreneurship, what barriers and enablers to entrepreneurship do they identify for themselves? 


\section{Methodology}

The research objectives of the study were to reveal the entrepreneurial intentions of computing students; to ask what factors might act as drivers encouraging take-up of entrepreneurship, and to explore the barriers and enablers to entrepreneurship, across two different institutions. A survey was developed to explore levels of interest, drivers (motivating factors), barriers and enablers associated with pursuing an entrepreneurial career. Two universities participated in the research study. An online survey was developed in Australia and adapted for use in the UK.

\section{Participants}

A total of 247 participants responded from a pool of 1200. Participants were all enrolled in computing courses at various levels; 177 were from the Australian university and 70 from the UK university. The online survey link was embedded in invitations sent by email. In the UK, only undergraduate students were invited to take part due to the timing of the survey. Responses that completed only participant background information were excluded from the analysis. Participant demographics are shown in Table 1. Although there were fewer female computing students (around 20\%), this is representative of computing courses in both Australia and the UK.

Table 1: Demographics

\begin{tabular}{|c|c|c|c|}
\hline \multicolumn{2}{|c|}{ Characteristic } & $\begin{array}{c}\text { Australia } \\
\text { Count (\%) }\end{array}$ & $\begin{array}{c}\text { UK } \\
\text { Count (\%) }\end{array}$ \\
\hline \multirow{2}{*}{ Gender } & Female & $29(16 \%)$ & $17(24 \%)$ \\
\hline & Male & 148 (84\%) & $53(76 \%)$ \\
\hline \multirow[t]{3}{*}{ Age } & Below 24 & 89 (50\%) & 34 (49\%) \\
\hline & 25 to 30 & 45 (25\%) & 13 (19\%) \\
\hline & 31 up & $44(25 \%)$ & 24 (33\%) \\
\hline \multirow[t]{2}{*}{ Level of study } & Undergraduate & 115 (65\%) & 70 (100\%) \\
\hline & Postgraduate & 61 (35\%) & $0(0 \%)$ \\
\hline
\end{tabular}

\section{Instrument}

The aim of the survey was to gather broad statistical information on the entrepreneurial intentions 
of computing students at each university then to explore whether gender and institutional context shape their career decisions. Questions included gender, age, level of study and a free-text option for career and entrepreneurship plans. Based on previous studies cited in the literature review, questions on drivers/motivations to take up entrepreneurship (9 items), barriers (10 items) and enablers (10 items) were included as five-point Likert scale statements. A score of five represented a high agreement and a score of one represented disagreement with the statement. The instrument was designed from a consolidation of factors suggested by various studies, thus a principal component analysis (PCA) was conducted to pool the various factors together prior to seeking significant differences. The PCA was conducted using varimax rotation and run separately for drivers, barriers and enablers. The overall Kaiser-Meyer-Olkin (KMO) sampling adequacy was met for each of the questions. Bartlett's test of sphericity was statistically significant $(\mathrm{p}<.0005)$ which indicates that the data was factorable. Internal reliability of each factor was assessed using Cronbach’s alpha.

Three factors emerged as reasons to take up entrepreneurship (drivers): external motivators (.725), internal motivators (.678) and job flexibility (.653). The barriers were categorised into three factors: internal or self-limiting factors (.746); external barriers (.634) and personal circumstances (.561). The enablers/support mechanisms were also categorised into three factors: idea generation (.835); policy (.821) and implementation support (.704). Appendix A contains a breakdown of the results of the PCA.

\section{Analysis}

Entrepreneurial intent was measured using the responses to the free-text question "Do you plan to become an entrepreneur?” and their reasons for that intent. Responses were coded into: yes, no, and maybe. Chi-square tests of homogeneity were run to compare the distribution of responses by participant age, gender and level of study (Table 2). Descriptive statistics (mean and standard deviation) at item and factor level were used to illustrate student perceptions of the importance of 
drivers, barriers and enablers affecting entrepreneurial intention (Table 3). To investigate gender and institutional differences, a two-way analysis of variance was carried out for each of the factors on drivers, barriers and enablers (Table 4).

\section{Results and discussion}

\section{Entrepreneurial intention}

Table 2 shows the percentages of students considering becoming IT entrepreneurs overall by university. The survey asked whether the participant planned to become an entrepreneur (i.e. had an intention to become an entrepreneur) and results showed that a high percentage of participants were interested in becoming entrepreneurs (38\%), and a significant percentage were still undecided (27\%), not yet having ruled out the possibility. By contrast, Shinnar et al. (2009) found considerably less interest among non-business school students (17\%), compared with the 35\% of business school students that were considering entrepreneurship in their study. A chi-square test of homogeneity was conducted between university and entrepreneurship plans. There was no statistically significant difference in the distribution of responses between students from Australia and the UK $\left(\mathrm{X}^{2}(2)=2.910, \mathrm{p}=.233\right)$. There was no significant difference in the distribution of responses for entrepreneurial intention by age and gender either in the UK or Australia. This counters previous studies which have found higher levels of interest amongst males than females (for example, Arranz, Arroyabe, and Fdez. de Arroyabe 2018; Thébaud 2010; Wilson, Kickul, and Marlino 2007). Factors leading to the high levels of interest could be the promotion of entrepreneurship activity at each campus and interest generated by the IT Entrepreneurship course offered at the Australian university. Nowinski et al. (2017) suggested an "entrepreneurshipfriendly atmosphere at universities” would increase entrepreneurship intentions (p 15). Alternatively, aspects of the computing subject discipline, the lack of women studying computing or the nature of entrepreneurial activity in the technology sector could be factors and deserve 
further consideration.

Table 2. Entrepreneurial intention by demographic

\begin{tabular}{|c|c|c|c|c|c|}
\hline \multirow{2}{*}{ Characteristic } & & \multicolumn{3}{|c|}{ Entrepreneurial intention } & \multirow[t]{2}{*}{ p-value } \\
\hline & & No & Undecided & Yes & \\
\hline \multirow[t]{4}{*}{ Australia } & Overall & $32.2 \%$ & $28.7 \%$ & $39.2 \%$ & \\
\hline & Below 24 & $29.8 \%$ & $29.8 \%$ & $40.5 \%$ & .371 \\
\hline & 25 to 30 & $27.3 \%$ & $25.0 \%$ & $47.7 \%$ & \\
\hline & 31 and above & $41.9 \%$ & $30.2 \%$ & $27.9 \%$ & \\
\hline \multirow[t]{2}{*}{ Gender } & Female & $44.4 \%$ & $25.9 \%$ & $29.6 \%$ & .326 \\
\hline & Male & $30.1 \%$ & $29.4 \%$ & $40.6 \%$ & \\
\hline \multirow[t]{2}{*}{ Level of study } & $\begin{array}{l}\text { Up to degree } \\
\text { level }\end{array}$ & $31.0 \%$ & $34.5 \%$ & $34.5 \%$ & .038 \\
\hline & $\begin{array}{l}\text { Postgraduate } \\
\text { level }\end{array}$ & $35.7 \%$ & $16.1 \%$ & $48.2 \%$ & \\
\hline \multirow{4}{*}{ Age } & Overall & $43.5 \%$ & $21.7 \%$ & $34.8 \%$ & \\
\hline & Below 24 & $51.5 \%$ & $18.2 \%$ & $30.3 \%$ & .556 \\
\hline & 25 to 30 & $46.2 \%$ & $15.4 \%$ & $38.5 \%$ & \\
\hline & 31 and above & $30.4 \%$ & $30.4 \%$ & $39.1 \%$ & \\
\hline \multirow[t]{2}{*}{ Gender } & Female & $41.2 \%$ & $29.4 \%$ & $29.4 \%$ & .662 \\
\hline & Male & $44.2 \%$ & $19.2 \%$ & $36.5 \%$ & \\
\hline \multirow[t]{2}{*}{ Level of study } & $\begin{array}{l}\text { Up to degree } \\
\text { level }\end{array}$ & $43.5 \%$ & $21.7 \%$ & $34.8 \%$ & - \\
\hline & $\begin{array}{l}\text { Postgraduate } \\
\text { level }\end{array}$ & - & - & - & \\
\hline
\end{tabular}

For the Australian participants, there was a significant difference in the distribution of entrepreneurial intention by level of study $\left(\mathrm{X}^{2}(2)=6.542, \mathrm{p}=.038\right)$. Post-hoc analysis involved pairwise comparisons using multiple z-tests of two proportions with a Bonferroni correction. There was a statistically significant difference in the proportion of undergraduate students versus postgraduate students who are not yet decided about their entrepreneurship plans (34.5\% for

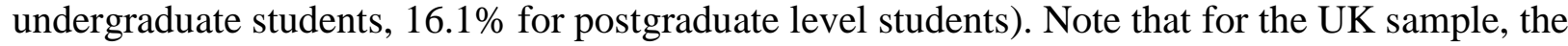
test was not run because all participants were at undergraduate level. Postgraduate students were less likely to be undecided about whether to take up entrepreneurship. Motivations for postgraduate study have been found to relate to personal/ career development and deferring entry to the job market (Ball 2016), and so it is unsurprising that a lower number of postgraduate 
participants were undecided in regard to entrepreneurship intentions as they are more likely to have better-developed personal/career goals than undergraduates.

\section{Drivers, barriers and enablers: all participants}

A comparison of student perceptions of the importance of drivers, barriers and enablers affecting entrepreneurial intention is shown in Table 3. Passion and job satisfaction were the two highest drivers (motivation factors) among all participants, which are also the items for intrinsic motivation. Within a Spanish context, Arranz et al. (2018) similarly found the most commonly cited reasons to become an entrepreneur were to develop ideas and for job satisfaction (in the form of 'desire for freedom' and 'taking my own decisions'): both highly motivating. Pruett et al. (2009) also found students to be motivated by job satisfaction gained through independence and autonomy in their study encompassing US, Spain and China.

Table 3. Descriptive statistics of motivation, barriers and enablers (item and scale level)

\begin{tabular}{lrr}
\hline \multicolumn{1}{c}{ Factors } & Mean & SD \\
\hline Motivations to take up entrepreneurship & & \\
Extrinsic motivation & 3.07 & $\mathbf{0 . 9 5}$ \\
Competitive graduate job market & 2.90 & 1.31 \\
Fame and recognition & 2.58 & 1.33 \\
Encouragement from family and friends & 2.78 & 1.40 \\
Opportunity to earn a high salary & 4.03 & 1.05 \\
Intrinsic motivation & $\mathbf{4 . 2 8}$ & $\mathbf{0 . 8 4}$ \\
Job satisfaction & 4.27 & 0.93 \\
Opportunity to follow my passion/interests & 4.28 & 1.00 \\
Flexible working options & 3.70 & $\mathbf{0 . 9 1}$ \\
Flexible working hours & 3.70 & 1.18 \\
Option of working from home & 3.58 & 1.19 \\
Being your own boss & 3.81 & 1.17 \\
\hline Perceived barriers in taking up entrepreneurship & & \\
Internal & 3.13 & $\mathbf{0 . 9 2}$ \\
Confidence & 3.40 & 1.30 \\
Lack of leadership skills & 2.54 & 1.29 \\
Not having found the right idea/concept & 3.51 & 1.32 \\
Fear of failure & 3.01 & 1.36 \\
Limited relevant experience & 3.19 & 1.25 \\
Lack of knowledge support to start a business & 3.82 & $\mathbf{0 . 8 5}$ \\
Lack of industry/network contacts & 3.65 & 1.19 \\
Finance & 3.80 & 1.08 \\
External & 4.02 & 1.03
\end{tabular}


Lack of support from family/friends $\quad 2.02 \quad 1.13$

$\begin{array}{lll}\text { Other personal circumstances } & \mathbf{2 . 2 4} & \mathbf{0 . 9 5}\end{array}$

$\begin{array}{lll}\text { Visa } & 1.98 & 1.39\end{array}$

Family/caring responsibilities $\quad 2.72 \quad 1.34$

Enablers/Support mechanisms

Idea generation

3.47

.94

Support and advice from academics

3.50

1.16

Participating in a university incubator/activator

3.46

1.20

Opportunities to discuss or brainstorm ideas

3.54

1.19

Education and training in entrepreneurship

3.76

1.12

Encouragement and support from my family

3.14

1.33

Policy

2.40

1.36

Changes to visa policy

1.49

Changes to government policy

1.47

Implementation

2.16

0.80

Help connecting to relevant industry

3.97

0.90

Financial support

4.04

1.06

Mentoring

3.95

1.05

3.91

1.05

External barriers comprising lack of knowledge, contacts, finance and support scored the highest at scale level. The barrier with the highest mean value was lack of finance (mean=4.02; $\mathrm{SD}=1.03$ ).

This finding is consistent with research cited earlier. In the technology sector, concern about running out of money has been found to affect attitudes and encourage fast-paced technology start-ups (Stayton \& Mangematin 2016). Finance as a barrier was followed by a lack of industry contacts (mean=3.80; $\mathrm{SD}=1.08$ ). This echoes findings from elsewhere, for example in a Malaysian context ( Singh Sandhu, Fahmi Sidique, and Riaz 2011).

The three items related to implementation of business ideas scored the highest as enablers. Help connecting to relevant industry (mean=4.04; $\mathrm{SD}=.90)$, financial support (mean=3.95; $\mathrm{SD}=1.06)$ and mentoring (mean=3.91; $\mathrm{SD}=1.05$ ) were the three top factors identified by participants to provide encouragement to take up entrepreneurship. These factors have been identified elsewhere (for example, Smith and Beasley 2011). The selection of these enabling factors is encouraging with respect to the role of universities which could clearly play a part through industry networking events, industry research projects, introducing students to investors and helping students find suitable mentors. Proximity to technology hubs has previously been shown to be beneficial to 
computing students, able to engage in activities such as meet-ups, hackathons and masterclasses which act to create industry awareness and links (Mtsweni and Abdullah 2015).

\section{Gender and institutional differences}

To investigate gender and institutional differences in how computing students perceived the different factors in relation to entrepreneurship a two-way analysis of variance was carried out for each of the scales following a test of homogeneity of variances. Descriptive statistics and ANOVA results are shown in Table 4.

\section{Drivers by gender and institution}

There was a significant gender and university interaction on the scale job flexibility $\left(\mathrm{F}(1,240)=9.402, \mathrm{p}=.002\right.$,partial $\left.\eta^{2}=.038\right)$. This was followed up by an analysis of simple main effect. There was a statistically significant gender difference in UK participants $(p=.003$, partial $\eta^{2}=.035$ ). The female participants in the UK rated job flexibility (comprising flexible working hours, option to work at home and being their own boss) higher (mean=4.21; sd=0.82) than UK male participants (mean=3.45; sd=0.95). This finding is in line with a study conducted in an Irish context (Humbert and Drew 2010). Gender difference was not significant for the Australian sample, however, there was a significant difference in the scores of female students between universities, $p=0.019$. The importance of job flexibility was higher for female participants in the UK than those from Australia (mean=3.55; $\mathrm{sd}=0.97$ ). In the UK, there is a strong preference for women to work flexibly (Timewise 2017) and access to free childcare for limited hours has been introduced. As for the male participants, there was also a significant difference by country, $\mathrm{p}=.034$. Male students from Australia scored job flexibility higher than the male students from the UK when considering becoming an entrepreneur. Studies from Australia note an increasing preference for flexible work, although more women than men currently work flexibly (Sanders et al. 2016). Promoting the possibilities of flexible working might encourage more computing 
students to embark on an entrepreneurial career.

For the extrinsic and intrinsic drivers, no significant interaction between gender and university was found (refer to Table 4). However, there was a main effect of university on the scores on these two subscales. In both subscales, Australian participants rated the importance of the factors higher than the UK participants. Participants from the Australian university rated job satisfaction, working from home, high salary, fame/recognition, job market and having a passion/interest significantly higher than UK participants. Indeed, overall the Australian participants seemed to recognise the entrepreneurship opportunity more positively than the UK participants. This might have been related to sampling whereby the Australian participants had studied an entrepreneurship course, whereas the UK participants were drawn from across all computing courses and would only have been passively aware of access to an incubator. 
Table 4. Descriptive statistics and F values for the two-way analysis of variance.

\begin{tabular}{|c|c|c|c|c|c|c|c|c|c|}
\hline \multirow[t]{2}{*}{ Factors } & \multicolumn{3}{|c|}{ Australia } & \multicolumn{3}{|c|}{ UK } & \multicolumn{3}{|c|}{$F$} \\
\hline & Overall & Female & Male & Overall & Female & Male & $\begin{array}{c}\text { Gender* } \\
\text { University }\end{array}$ & Gender & $\begin{array}{c}\text { Universit } \\
\mathrm{y}\end{array}$ \\
\hline \multicolumn{10}{|l|}{ Motivations } \\
\hline Extrinsic & $3.19(0.89)$ & $3.27(0.66)$ & $3.18(0.93)$ & $2.75(1.02)$ & $2.75(0.94)$ & 2.75 & .086 & .070 & $8.209 *$ \\
\hline Intrinsic & $4.38(0.72)$ & $4.32(0.77)$ & $4.38(0.72)$ & $4.04(1.05)$ & $4.09(1.16)$ & 4.02 & .222 & .002 & $4.113^{*}$ \\
\hline Flexibility & $3.73(0.88)$ & 3.55 (0.97) & $3.76(0.87)$ & $3.63(0.97)$ & $4.21(0.82)$ & 3.45 & $9.402^{* *}$ & 2.967 & 1.258 \\
\hline \multicolumn{10}{|l|}{ Barriers } \\
\hline Internal & $3.16(0.92)$ & 3.59 (1) & $3.07(0.88)$ & $3.05(0.93)$ & $2.95(0.88)$ & 3.09 & $4.409 *$ & 1.562 & $3.909 *$ \\
\hline External & $3.89(0.76)$ & $4.03(0.74)$ & $3.86(0.77)$ & $3.64(1.01)$ & $3.9(0.89)$ & 3.55 & .374 & 3.226 & 2.332 \\
\hline Others & $2.36(0.98)$ & $2.42(1.04)$ & $2.34(0.97)$ & $1.95(0.81)$ & $2.06(0.87)$ & $1.92(0.8)$ & .040 & .477 & $5.918 *$ \\
\hline \multicolumn{10}{|l|}{ Enablers } \\
\hline Idea & $3.57(0.87)$ & $3.72(0.88)$ & $3.54(0.87)$ & $3.23(1.05)$ & $3.6(1.1)$ & 3.11 & .979 & $4.449 *$ & 2.951 \\
\hline Policy & $2.52(1.42)$ & 2.69 (1.33) & $2.5(1.43)$ & $2.1(1.17)$ & $2.29(1.21)$ & 2.04 & .020 & .913 & 3.377 \\
\hline Support & $4.01(0.8)$ & $4.05(0.97)$ & $4(0.76)$ & $3.87(0.81)$ & $4.1(0.86)$ & $3.8(0.78)$ & .830 & 1.590 & .284 \\
\hline
\end{tabular}




\section{Barriers by gender and institution}

There was a significant gender and country interaction following a two-way analysis of variance on the subscale internal barriers $\left(\mathrm{F}(1,241)=4.409, \mathrm{p}=.037\right.$, partial $\left.\eta^{2}=.018\right)$. Follow up simple main effect found a significant gender difference for the Australian sample $(p=.005)$. Female students scored the items in relation to internal barriers higher (mean=3.59, sd=1.0) than male students (mean=3.07; sd=.088). A comparison of the scores of female students by country also showed a significant difference $(p=.022)$. Female students from Australia also scored higher than female students from the UK (mean=2.95; sd=0.88). No other significant pairwise comparisons were found. Identification of such barriers is consistent with similar gendered approaches to risk observed elsewhere (for example, Humbert and Brindley 2015). The Australian female students cited a lack of confidence, lack of leadership skills, not having found the right idea, fear of failure and concern about having limited relevant experience: indeed, barriers were a more significant concern amongst Australian females. This could perhaps be explained by an Australian aversion to uncertainty compounding gendered preferences (Hofstede 2018). Suggestions for increasing relevant experience include support to build industry contacts (Seet et al. 2018), mentors (Ahsan et al. 2018) and role models (Pruett et al. 2009; BarNir, Watson, and Hutchins 2011). Other studies have, for example, shown women with access to entrepreneurship education expressing greater levels of entrepreneurship self-efficacy related to entrepreneurship activity (Nowiński et al. 2017) and women entrepreneurs expressing a need for competence which could be built through gaining expertise, training and networking (Murphy 2017). By comparison, the lower ratings for barriers among UK female student responses could be explained by the local environment. The UK university is located in a city with a large and growing IT entrepreneurship ecosystem where startups routinely offer student internships and graduate jobs, and access to the IT sector is facilitated by staff in the university. Furthermore, the UK university has a history of entrepreneurship which is promoted during the application cycle. Such activity has been found to affect intention (for 
example, Shirokova, Osiyevskyy, and Bogatyreva 2016).

For the subscale other personal circumstances there was a main effect of country on the subscale scores. Australian students (mean=2.36, $s d=0.98$ ) rated the scale higher than the UK students (mean=1.95; sd=0.81) The difference in samples could explain this - as a higher proportion of the Australian participants were international students (more likely to be pre-occupied with Visas) and Masters-level (more likely to have family commitments), however the ratings are very close to 2.5 which suggests neutrality on this factor. There were no significant differences found on the subscale external barriers.

\section{Enablers by gender and institution}

There were gender differences found on the subscale idea generation following a test of main effect from a non-significant two-way interaction of gender and university

$\left(\mathrm{F}(1,242)=4.499, \mathrm{p}=.035\right.$, partial $\left.\eta^{2}=.012\right)$. However, this effect can be considered small. While no significant differences were found on the subscale policy and implementation, female participants on average rated the importance of idea generation higher (mean=3.67; sd=.96) than male participants (mean=3.42; sd=.93). Idea generation comprised academic support, access to an incubator, opportunities to brainstorm, education \& training and family encouragement \& support. Apart from family support, all other factors are within the remit of an entrepreneurial university. Resourcing and promoting such enablers in an inclusive manner might increase entrepreneurship. Previous studies have shown women to benefit more than men from business incubators, largely through building social and business contacts (Amezcua 2010). The provision of business incubators enables broader discussion of industry requirements including how to market, test and shape IT ventures, all with potential to increase confidence. However incubators need to be promoted in ways that help students recognise the benefits. 


\section{Conclusion}

The decision to pursue a career as an entrepreneur is shaped by a range of individual realities such as educational, socio-cultural, gendered factors and labour market conditions. This paper presented entrepreneurial intentions, drivers, barriers and enablers to better understand computing students' attitudes towards entrepreneurship. This topic is important as entrepreneurship is key to economic growth/ recovery and increasingly seen by universities as part of their graduate employability remit. Subsequent analysis of the findings revealed differences which could be used to better understand how universities can support entrepreneurship in computing students.

Overall, we found high levels of interest among both female and male computing students which is encouraging for universities that encourage entrepreneurship and those governments and policymakers promoting economic growth through technology. Participants were motivated by a passion for their subject and for the possibility of job satisfaction. Barriers (limited access to finance, contacts, knowledge and experience) were scored higher by women than men, and women rated the importance of enablers such as business incubators and education \& training more highly than men.

The main recommendations are fourfold: (i) for universities to consider subject discipline, gender and context when promoting resources designed to increase awareness of the entrepreneurship opportunity, for example signposting flexible working rather than wealth creation; (ii) to build student confidence through external engagement and introducing investor organisations and other funding sources; (iii) to offer opportunities to develop business ideas through the provision of a business incubator and consequent activity in order to reduce perceptions of barriers amongst computing students, especially women; (iv) education policy-makers should ask universities to consider inclusion through their third mission imperatives. As the computing discipline seeks to achieve a better gender balance, graduate destinations must also be balanced to ensure the pipeline in and through university leads to fair outcomes. Approaches that are context and gender-specific 
might overcome barriers to pursuing entrepreneurship, and may help redress the masculine subjective norms proliferating in the field of entrepreneurship. There is a chance, then, of inclusive economic growth.

This study has limitations. Only two universities were used in the study and each had recently invested in, and promoted, business incubators. A wider study incorporating universities with different approaches to entrepreneurship would be useful to reveal whether the universities initiatives had directly acted to increase entrepreneurial intentions.

Acknowledgements This work was funded by an SRHE Research Award. We thank Rob Gresham and the SRHE for enabling financial support and advice. We acknowledge the support of Professors Margaret Jollands, Kay Latham, Liz Bacon and Lachlan McKinnon, Dr Cate Gribble, Dr Mark Rahimi, Dr Tanja Capic and Cilla Richards.

\section{References}

Ahsan, Mujtaba, Congcong Zheng, Alex DeNoble, and Martina Musteen. 2018. "From Student to Entrepreneur: How Mentorships and Affect Influence Student Venture Launch.” Journal of Small Business Management 56 (1): 76-102.

Al-Dajani, Haya, Evangelos Dedoussis, Erika Watson, and Nikolaos Tzokas. 2014. “Graduate Entrepreneurship Incubation Environments: A Framework of Key Success Factors.” Industry and Higher Education 28 (3): 201-213. https://doi.org/10.5367/ihe.2014.0205.

Amezcua, Alejandro. 2010. Boon or Boondoggle? Business incubation as entrepreneurship policy. PHD Thesis, Syracuse University.

Arranz, N, M F Arroyabe, and J. C. Fdez. de Arroyabe. 2018. "Entrepreneurial Intention and Obstacles of Undergraduate Students: The Case of the Universities of Andalusia.” Studies in Higher Education, June, 1-14. https://doi.org/10.1080/03075079.2018.1486812.

Audretsch, David, Max Keilbach, and Erik E Lehmann. 2006. Entrepreneurship and Economic Growth. Oxford, UK: Oxford University Press. https://doi.org/10.1093/acprof:oso/9780195183511.001.0001. 
Ball, Charlie. 2016. “Learning from Futuretrack: Deciding to Undertake Postgraduate Study.” http://dera.ioe.ac.uk/26487/1/learning-from-futuretrack.pdf.

BarNir, Anat, Warren Watson, and Holly Hutchins. 2011. "Mediation and Moderated Mediation in the Relationship Among Role Models , Self-Efficacy , Entrepreneurial Career Intention , and Gender.” Journal of Applied Psychology 41 (2): 270-97. https://doi.org/10.1111/j.15591816.2010.00713.x.

Carsrud, Alan, and Malin Brännback. 2011. "Entrepreneurial Motivations: What Do We Still Need to Know.” Journal of Small Business Management 49 (1): 9-26.

Casson, Mark, and Marina Della Giusta. 2007. “Entrepreneurship and Social Capital: Analysing the Impact of Social Networks on Entrepreneurial Activity from a Rational Action Perspective.” International Small Business Journal 25 (3): 220-44. https://doi.org/10.1177/0266242607076524.

Engelen, Andreas. 2010. “Entrepreneurial Orientation as a Function of National Cultural Variations in Two Countries.” Journal of International Management Entrepreneurial 16 (4): 354-68. https://doi.org/10.1016/j.intman.2010.09.006.

Falkner, Katrina. 2017. “A look at IT and Egineering Enrolments in Australia - Updated! ”, Available at: https://blogs.adelaide.edu.au/cser/2017/02/15/a-look-at-it-and-engineeringenrolments-in-australia-updated/

Feder, Emőke-Szidónia, and Renata-Dana Niţu-Antonie. 2017. “Connecting Gender Identity, Entrepreneurial Training, Role Models and Intentions.” International Journal of Gender and Entrepreneurship 9 (1): 87-108. https://doi.org/10.1108/IJGE-08-2016-0028.

Frank, Robert, Pierre Marques, and Frank Lasch. 2009. “Entrepreneurship in Emerging High-Tech Industries : ICT Entrepreneurs between Experts and Kamikazes” International Journal of Entrepreneurship and Small Business 7 (3): 258-83. https://doi.org/10.1504/IJESB.2009.023020.

Galloway, Laura, Isla Kapasi, and Geoff Whittam. 2015. “Exploring 'Successful’ Outcomes of Entrepreneurship Education.” Industry and Higher Education 29 (6): 505-15. https://doi.org/10.5367/ihe.2015.0281. 
Guerrero, Maribel, David Urbano, James A. Cunningham, and Eduardo Gajón. 2018.

“Determinants of Graduates’ Start-Ups Creation across a Multi-Campus Entrepreneurial University: The Case of Monterrey Institute of Technology and Higher Education.” Journal of Small Business Management 56 (1): 150-78. https://doi.org/10.1111/jsbm.12366.

Hart, Mark, Karen Bonner, Jonathon Levie, and Laura Heery. 2017. "Global Entrepreneurship Monitor UK" http://www.aston.ac.uk/aston-business-school/research/working-withbusiness/gem/

HESA, 2017. "What do HE students study," Available: https://www.hesa.ac.uk/data-andanalysis/students/what-study.

Hofstede, Geert. 2018. “Hofstede Insights: Country Comparison.” Available: https://www.hofstede-insights.com/country-comparison/australia,the-uk/.

Humbert, Anne, and Clare Brindley. 2015. “Challenging the Concept of Risk in Relation to Women’s Entrepreneurship.” Gender in Management: An International Journal 30 (1): 2-25. https://doi.org/10.1108/GM-10-2013-0120.

Humbert, Anne, and Eileen Drew. 2010. “Gender, Entrepreneurship and Motivational Factors in an Irish Context.” International Journal of Gender and Entrepreneurship. https://doi.org/10.1108/17566261011051026.

Jabeen, Fauzia, Mohd. Nishat Faisal, and Marios Katsioloudes. 2017. "Entrepreneurial Mindset and the Role of Universities as Strategic Drivers of Entrepreneurship.” Journal of Small Business and Enterprise Development 24 (1): 136-57. https://doi.org/10.1108/JSBED-072016-0117.

Jansen, Slinger, Tommy Van De Zande, Sjaak Brinkkemper, Erik Stam, and Vasudeva Varma. 2015. "How Education, Stimulation, and Incubation Encourage Student Entrepreneurship: Observations from MIT, IIIT, and Utrecht University.” International Journal of Management Education 13 (2): 170-81. https://doi.org/10.1016/j.ijme.2015.03.001.

Kaltenecker, Natalie, Christian Hoerndlein, and Thomas Hess. 2015. “The Drivers of Entrepreneurial Intentions - an Empirical Study Among Information Systems and Computer Science Students.” Journal of Entrepreneurship Education 18 (2): 39-52. 
Kwon, Seok-Woo, and Pia Arenius. 2010. "Nations of Entrepreneurs: A Social Capital Perspective 氶.” Journal of Business Venturing 25 (3): 315-30. https://doi.org/10.1016/j.jbusvent.2008.10.008.

Kwong, Caleb, Dylan Jones-Evans, and Piers Thompson. 2012. "Differences in Perceptions of Access to Finance between Potential Male and Female Entrepreneurs.” International Journal of Entrepreneurial Behavior \& Research 18 (1): 75-97. https://doi.org/10.1108/13552551211201385.

Leadem, R. 2016. “Female Entrepreneurship Is on the Rise.” Entrepreneur. 2016. https://www.entrepreneur.com/article/285656.

Light, Ivan, and Léo Paul Dana. 2013. "Boundaries of Social Capital in Entrepreneurship.” Entrepreneurship: Theory and Practice 37 (3): 603-24. https://doi.org/10.1111/etap.12016.

Marlow, Susan, and Dean Patton. 2005. “All Credit to Men?Entrepreneurship, Finance, and Gender.” Entrepreneurship: Theory and Practice 20 (6): 717-35. https://doi.org/10.1111/j.1540-6520.2005.00105.x.

McClelland, David. 1987. “Characteristics of Successful Entrepreneurs.” Journal of Creative Behaviour 21 (3): 219-33. https://doi.org/10.1002/j.2162-6057.1987.tb00479.x.

Miller, Danny. 2015. “A Downside to the Entrepreneurial Personality?” Entrepreneurship: Theory and Practice 39 (1): 1-8. https://doi.org/10.1111/etap.12130.

Morris, Michael H., Xaver Neumeyer, Yongseok Jang, and Donald F. Kuratko. 2018. “Distinguishing Types of Entrepreneurial Ventures: An Identity-Based Perspective.” Journal of Small Business Management 56 (3): 453-74. https://doi.org/10.1111/jsbm.12272.

Mtsweni, Jabu, and H Abdullah. 2015. “Stimulating and Maintaining Students’ Interest in Computer Science Using the Hackathon Model.” The Independent Journal of Teaching and Learning 10 (1): 85-97.

Murphy, Dianne. 2017. “A Model of Women Entrepreneurs’ Well-Being.” University of Wisconsin Milwaukee. http://dc.uwm.edu/etdhttp://dc.uwm.edu/etd/1516.

Nabi, Ghulam, Francisco Liñan, Alain Fayolle, Norris Krueger, and Andreas Walmsley. 2017. “The Impact of Entrepreneurship Education in Higher Education: A Systematic Review and 
Research Agenda.” Academy of Management Learning \& Education 16 (2): 277-99. https://doi.org/10.5465/amle.2015.0026.

Naudé, Wim. 2014. “Entrepreneurship and Economic Development.” In International Development: Ideas, Experience, and Prospects, edited by Bruce Currie-Alder, Ravi Kanbur, David Malone, and Rohinton Medhora, 311-22. Oxford, UK: Oxford University Press. https://doi.org/10.1093/acprof:oso/9780199671656.003.0019.

Nowiński, Witold, Mohamed Yacine Haddoud, Drahoslav Lančarič, Dana Egerová, and Csilla Czeglédi. 2017. “The Impact of Entrepreneurship Education, Entrepreneurial Self-Efficacy and Gender on Entrepreneurial Intentions of University Students in the Visegrad Countries.” Studies in Higher Education, August, 1-19. https://doi.org/10.1080/03075079.2017.1365359.

OECD. 2017. Entrepreneurship at a Glance 2017. OECD Publishing.

Pruett, Mark, Rachel Shinnar, Bryan Toney, Francisco Llopis, and Jerry Fox. 2009. “Explaining Entrepreneurial Intentions of University Students: A Cross-Cultural Study Article Information.” International Journal of Entrepreneurial Behavior and Research 15 (6): 57194. https://doi.org/10.1108/13552550910995443.

Rae, David, and Douglas E Melton. 2014. "Developing an Entrepreneurial Mindset in US Engineering Education: An International View of the KEEN Project.” Vol. 7. http://www.jeenonline.com/Vol7/Num3/Paper_01-web.pdf.

Sanders, Melanie, Jennifer Zeng, Meredith Hellicar, and Kathryn Fagg. 2016. “The Power of Flexibility: A Key Enabler to Boost Gender Parity and Employee Engagement -.” 2016. http://www.bain.com/publications/articles/the-power-of-flexibility.aspx.

Santos, Francisco J., Muhammad Azam Roomi, and Francisco Liñán. 2016. “About Gender Differences and the Social Environment in the Development of Entrepreneurial Intentions.” Journal of Small Business Management 54 (1): 49-66. https://doi.org/10.1111/jsbm.12129.

Sauer, Robert M, and Tanya Wilson. 2016. “The Rise of Female Entrepreneurs: New Evidence on Gender Differences in Liquidity Constraints.” European Economic Review 86: 73-86. https://doi.org/10.1016/j.euroecorev.2015.10.010.

Schneider, Aaron. 2017. “Social Entrepreneurship, Entrepreneurship, Collectivism, and 
Everything in Between: Prototypes and Continuous Dimensions.” Public Administration Review 77 (3): 421-31. https://doi.org/10.1111/puar.12635.

Schoon, Ingrid, and Kathryn Duckworth. 2012. "Who Becomes an Entrepreneur? Early Life Experiences as Predictors of Entrepreneurship.” Developmental Psychology 48 (6): 1719-26. https://doi.org/10.1037/a0029168.

Seet, Pi-Shen, Janice Jones, Lloyd Oppelaar, and Graciela Corral de Zubielqui. 2018. "Beyond 'Know-What' and 'Know-How' to 'Know-Who': Enhancing Human Capital with Social Capital in an Australian Start-up Accelerator.” Asia Pacific Business Review 24 (2): 233-60. https://doi.org/10.1080/13602381.2018.1431250.

Shinnar, Rachel, Olivier Giacomin, and Frank Janssen. 2012. "Entrepreneurial Perceptions and Intentions: The Role of Gender and Culture.” Entrepreneurship: Theory and Practice 36 (3): 465-93. https://doi.org/10.1111/j.1540-6520.2012.00509.x.

Shinnar, Rachel, Dan Hsu, Benjamin Powell, and Haibo Zhou. 2018. "Entrepreneurial Intentions and Start-Ups: Are Women or Men More Likely to Enact Their Intentions?” International Small Business Journal: Researching Entrepreneurship 36 (1): 60-80. https://doi.org/10.1177/0266242617704277.

Shinnar, Rachel, Mark Pruett, and Bryan Toney. 2009. "Entrepreneurship Education: Attitudes Across Campus.” Journal of Education for Business 84 (3): 151-59. https://doi.org/10.3200/JOEB.84.3.151-159.

Shirokova, Galina, Oleksiy Osiyevskyy, and Karina Bogatyreva. 2016. “Exploring the Intentionebehavior Link in Student Entrepreneurship: Moderating Effects of Individual and Environmental Characteristics.” European Management Journal 34: 386-99. https://doi.org/10.1016/j.emj.2015.12.007.

Singh Sandhu, Manjit, Shaufique Fahmi Sidique, and Shoaib Riaz. 2011. "Entrepreneurship Barriers and Entrepreneurial Inclination among Malaysian Postgraduate Students.” International Journal of Entrepreneurial Behavior \& Research 17 (4): 428-49. https://doi.org/10.1108/13552551111139656.

Smith, Kelly, and Martin Beasley. 2011. “Graduate Entrepreneurs: Intentions, Barriers and Solutions.” Edited by Harry Matlay. Education + Training 53 (8/9): 722-40. 
https://doi.org/10.1108/00400911111185044.

Startup Muster. 2017. “Startup Muster 2017 Annual Report.” 2017.

https://www.startupmuster.com/reports/Startup-Muster-2017-Report.pdf.

Stayton, John, and Vincent Mangematin. 2016. "Startup time, innovation and organizational emergence: A study of USA-based international technology ventures." Journal of International Entrepreneurship 14, no. 3: 373-409.

Teixeira, Aurora, and R Forte. 2017. "Prior Education and Entrepreneurial Intentions: The Differential Impact of a Wide Range of Fields of Study.” Review of Managerial Science 11 (2): 353-94. https://doi.org/10.1007/s11846-015-0188-2.

Thébaud, Sarah. 2010. “Gender and Entrepreneurship as a Career Choice: Do Self-Assessments of Ability Matter?” Social Psychology Quarterly 73 (3): 288-304. https://doi.org/10.1177/0190272510377882.

Timewise. 2017. “Flexibile Working: A Talent Imperative.” 2017. https://timewise.co.uk/wpcontent/uploads/2017/09/Flexible_working_Talent_-Imperative.pdf.

Urbano, David, Sebastian Aparicio, and David Audretsch. 2018. “Twenty-Five Years of Research on Institutions, Entrepreneurship, and Economic Growth: What Has Been Learned?” Small Business Economics, April. https://doi.org/10.1007/s11187-018-0038-0.

Wang, Clement K, and Poh-Kam Wong. 2004. "Entrepreneurial Interest of University Students in Singapore.” Technovation 24: 163-72. https://doi.org/10.1016/S0166-4972(02)00016-0.

Watson, Derek, Lynne Hall, and Sarah Tazzyman. 2016. "Trick or treat: Academic buy-in to third stream activities." Industry and Higher Education 30, no. 2: 155-167.

Wilson, Fiona, Jill Kickul, and Deborah Marlino. 2007. “Gender, Entrepreneurial Self-Efficacy, and Entrepreneurial Career Intentions: Implications for Entrepreneurship Education.” Education, no. 617: 387-407. https://doi.org/10.1111/j.1540-6520.2007.00179.x.

Zhao, Hao, Scott E Seibert, and Gerald E Hills. 2005. “The Mediating Role of Self-Efficacy in the Development of Entrepreneurial Intentions.” Journal of Applied Psychology 90 (6): 1265-72. https://doi.org/10.1037/0021-9010.90.6.1265. 
Appendix A. PCA Results for motivators, barriers and enablers

Table A1. PCA for reasons in taking up entrepreneurship

\begin{tabular}{|c|c|c|c|}
\hline & $\begin{array}{c}\text { Extrinsic } \\
\text { motivation } \\
.725 \\
\end{array}$ & $\begin{array}{c}\text { Intrinsic } \\
\text { motivation } \\
.678 \\
\end{array}$ & $\begin{array}{c}\text { Job } \\
\text { Flexibility } \\
.653 \\
\end{array}$ \\
\hline Competitive graduate job market & .809 & & \\
\hline Fame and recognition & .760 & & \\
\hline Encouragement from family and friends & .684 & & \\
\hline Opportunity to earn a high salary & .603 & & \\
\hline Job satisfaction & & .830 & \\
\hline Opportunity to follow my passion/interests & & .786 & \\
\hline Flexible working hours & & & .829 \\
\hline Option of working from home & & & .777 \\
\hline Being your own boss & & .494 & .566 \\
\hline Variance explained & $33.58 \%$ & $16.40 \%$ & $12.38 \%$ \\
\hline
\end{tabular}

Factor loadings below .4 are suppressed.; $\mathrm{KMO}=.751$

Table A2. PCA for barriers

\begin{tabular}{|c|c|c|c|}
\hline & $\begin{array}{c}\text { Internal/ } \\
\text { Self } \\
.746\end{array}$ & $\begin{array}{c}\text { External } \\
.634\end{array}$ & $\begin{array}{c}\text { Personal } \\
\text { circumstances } \\
.561\end{array}$ \\
\hline Confidence & .758 & & \\
\hline Lack of leadership skills & .691 & & \\
\hline Not having found the right idea/concept & .671 & & \\
\hline Fear of failure & .645 & & \\
\hline Limited relevant experience & .595 & & \\
\hline $\begin{array}{l}\text { Lack of support and/or knowledge to start a } \\
\text { business }\end{array}$ & & .801 & \\
\hline Lack of industry/network contacts & & .697 & \\
\hline Finance & & .679 & \\
\hline Lack of support from family/friends & & & .782 \\
\hline Visa & & & .780 \\
\hline Family/caring responsibilities & & & .567 \\
\hline Variance explained & $31.53 \%$ & $13.18 \%$ & $10.17 \%$ \\
\hline
\end{tabular}

$\mathrm{KMO}=.738$. Administrative barrier was removed from the analysis due to low factor loading. 


\begin{tabular}{lccc}
\hline & Idea & & \\
& Generation & Policy & Implementation \\
& .835 & .821 & .704 \\
\hline Support and advice from academics & .792 & & \\
Participating in a university incubator/activator & .779 & & \\
Opportunities to discuss or brainstorm ideas & .764 & & \\
Education and training in entrepreneurship & .680 & & \\
Encouragement and support from my family & & & \\
$\quad$ and friends & .656 & & .550 \\
Changes to visa policy & & .895 & .835 \\
Changes to government policy & & & .873 \\
Help connecting to relevant industry & & & .567 \\
Financial support & & & \\
Mentoring & $46.15 \%$ & $13.94 \%$ & $9.28 \%$ \\
Variance explained & &
\end{tabular}

$\mathrm{KMO}=.860$ 